\title{
LIGAÇÕES PERIGOSAS: COMUNICAÇÃO E RESPONSABILIDADE SOCIAL EMPRESARIAL
}

\author{
GISELA GONÇALVES \\ Universidade da Beira Interior | LabCom \\ Covilhã, Portugal \\ email: gisela.ubi@gmail.com
}


LIGAÇÕES PERIGOSAS: COMUNICAÇÃO E RESPONSABILIDADE SOCIAL EMPRESARIAL

Resumo: Neste artigo problematiza-se a complexidade inerente às estratégias de comunicação das políticas de responsabilidade social empresarial (RSE) a partir da perspetiva de um grupo de diretores de comunicação e consultores de relações públicas a operar no mercado português. As estratégias e projetos chamados de socialmente responsável serão reais indicadores de mudanças empresariais genuínas? Ou serão as políticas de RSE insinceras per se e a sua comunicação uma mera invenção das relações públicas? Os princípios centrais da comunicação da RSE são evidenciados, assim como o papel das relações públicas na gestão ética das relações organização-públicos.

Palavras chave: Responsabilidade social empresarial; relações públicas; ética; Portugal.

RELACIONES PELIGROSAS: COMUNICACIÓN Y RESPONSABILIDAD SOCIAL DE LAS EMPRESAS

Resumen: En este texto se discute la complejidad inherente a las estrategias de comunicación de las políticas de responsabilidad social corporativa desde la perspectiva de un grupo de directores de comunicación y consultores de relaciones públicas que actúa en el mercado portugués. ¿Las estrategias y proyectos llamados socialmente responsables son los indicadores reales de verdaderos cambios corporativos? ¿O es la RSC insincera per se y la comunicación una mera invención de las RP? Los principios centrales de la comunicación de la RSE son evidenciados, así como el papel de las relaciones públicas en la gestión ética de las relaciones entre una organización y sus públicos.

Palabras clave: Responsabilidad social corporative; relaciones públicas; ética; Portugal.

\section{DANGEROUS LIAISONS: COMMUNICATION AND CORPORATE SOCIAL RESPONSIBILITY}

Abstract: From the perspective of a group of public relations consultants and communication directors operating in Portugal, this paper discusses the complexity inherent to CSR communication. Are so-called sustainable and socially responsible business strategies and projects, in fact, indicators of genuine corporate change? Or is CSR per se insincere and CSR communication a mere invention of PR? Some core principles for communicating CSR are highlighted, as well as to the role of public relations in the ethical management of organization-publics relationship.

Keywords: Corporate social responsibility; public relations; ethics; Portugal. 


\section{INTRODUÇÃO}

A responsabilidade social das empresas (RSE), definida no Livro Verde da Comissão Europeia, em 2001, como "um conceito segundo o qual as empresas decidem, numa base voluntária, contribuir para uma sociedade mais justa e para um ambiente mais limpo", continua hoje no centro das atenções, tanto das organizações como da opinião pública. ${ }^{1}$ Nos websites das empresas, nos relatórios anuais de sustentabilidade, em eventos e nos media, os públicos têm sido alvo de uma explosão retórica sobre a sustentabilidade ambiental e o respeito pelos direitos humanos. No entanto, para muitos observadores e grupos de activistas a questão que prevalece é a seguinte: São as estratégias e projectos chamados de socialmente responsável e sustentável, reais indicadores de políticas empresariais genuínas? Ou será a RSE insincera per se a e uma mera "invenção das RP”, como argumenta Frankental (2001)?

Partindo do princípio que estas questões apenas podem ser respondidas empresa a empresa, isto é, situacionalmente, neste artigo centramos atenções nas perspectivas dos agentes de comunicação - directores de comunicação e consultores de comunicação - em relação à comunicação das políticas de responsabilidade empresarial. Com esse objectivo em mente, começamos por apresentar a evolução do conceito de RSE centrando atenções na tensão, desde sempre presente, entre os movimentos activistas, a regulação governamental e o discurso e acção empresarial.

Com esta reflexão procura-se contribuir para a discussão sobre o papel dos profissionais de relações públicas na tomada de decisões sobre o quê, como e quando comunicar sobre a responsabilidade empresarial e, assim, oferecer elementos para uma maior compreensão deste importante campo profissional.

\section{RESPONSABILIDADE EMPRESARIAL - ENTRE OS MOVIMENTOS AC- TIVISTAS E A REGULAÇÃO GOVERNAMENTAL}

Nos últimos anos, a responsabilidade social empresarial (RSE), a sustentabi-

1 Ver: Promover um quadro europeu para a responsabilidade social das empresas. Disponível em http://eur-lex.europa.eu/LexUriServ/site/pt/com/2001/com2001_0366pt01.pdf. Acesso em 25/06/2012. 
lidade e accountability das empresas tem estado no centro das atenções, tanto dos negócios como da investigação académica. Este facto reflecte uma tendência corrente e crescente na prática empresarial de integrar as questões ambientais e os direitos humanos nas suas operações. Como consequência, cada vez mais empresas conduzem programas de comunicação assentes na questão da RSE.

No entanto, enquanto muitos gestores de topo e profissionais de relações públicas argumentam que as empresas estão cada vez mais séria e conscientemente orientadas para o caminho da RSE, vários são os investigadores e grupos críticos que duvidam desta assunção. Muitos são os que acusam o mundo empresarial de práticas de "greenwash"'(habitualmente traduzido por "esverdeamento' ou 'branqueamento ecológico'), ao disseminarem informação enganosa sobre a performance ambiental e social, com o objectivo de criar uma imagem favorável da organização, com o consequente retorno nos negócios.

De acordo com os manuais mais reconhecidos de relações públicas (e.g., Cutlip, Center e Broom, 1986; Grunig e Hunt, 1984; Lesley, 1991), até aos anos 50, a acção das relações públicas empresariais centrava-se na disseminação de informação, em modelos de comunicação unidireccional, sem qualquer consideração pelo feedback dos públicos ou audiências. A partir dos anos 50, em grande parte devido ao surgimento da televisão - um novo meio capaz de moldar a opinião pública - os modelos de comunicação promovidos pelas relações públicas passam a ser bidireccionais. Edward L. Bernays, considerado o pai das relações públicas científicas, é bem representativo desta evolução, ao centrar a sua actividade na pesquisa dos públicos, no feedback das audiências e na avaliação das atitudes da massa. O conceito de "engenharia do consenso" (Bernays, 1955) impunha-se à época como sinónimo do poder das relações públicas no aconselhamento de empresas sobre a melhor forma de obter o consentimento público sobre as suas operações e de ultrapassarem problemas relacionados com políticas públicas.

É precisamente no início da segunda metade do séc. XX que o sentimento

2 O termo "greenwash" foi cunhado pelo ambientalista de Nova-iorquino, Jay Westerveld, num ensaio crítico de 1986, sobre o abuso da popularidade do movimento verde pela indústria hoteleira (Hayward, 2009). A vulgarização do termo greenwash tem vindo a ser acompanhada pelo conceito de bluewash. Isto é, o esforço desenvolvido pelas empresas para serem percebidas como parte da comunidade humanitária mundial através da associação voluntária com as Nações Unidas. 
anti-negócio ganha força nos EUA e, um pouco mais tarde, também na Europa. Poder nuclear, abuso dos direitos civis, o movimento dos direitos da mulher e do consumidor, são alguns dos exemplos que contribuíram para a tensão entre negócios e sociedade. O consenso público, antes referido, estava em risco devido ao activismo e ao cepticismo público, e novas capacidades de gestão e de comunicação eram exigidas às empresas.

Neste contexto, é natural que o conceito de RSE tenha evoluído exponencialmente. De acordo com a síntese desenvolvida por Carrol (1999, p. 270), na década de 50, o conceito de RSE entra na era moderna com a publicação de Social Responsibilities of the Businessman, de Howard Bowen (1953). Como o título indica, o autor questiona quais as obrigações dos líderes empresariais no sentido de perseguir "políticas, tomar decisões ou seguir linhas de acção que são desejáveis no que respeita aos valores e aos objectivos da nossa sociedade" (Bowen, 1953, p. 11). Segundo Cochran (2007), será nos anos 60, 70, que o conceito de RSE sofre uma das suas mais interessantes evoluções, visível no muito citado texto de William Frederick (1978): From CSR1 to CSR2: The Maturing of Business-and-Society Thought: as empresas deixaram de estar simplesmente envolvidas no debate académico sobre a ética dos diferentes graus de RSE, para começaram a responder de forma pragmática às várias pressões sociais. Quer dizer que à medida que os grupos activistas aprimoravam a sua forma de pressão através do recurso aos media, também as empresas reagiam com a modificação dos seus produtos e das suas políticas de gestão.

Nas últimas décadas do século XX o grau de respostas empresariais à pressão ativista cresceu de forma dramática. O movimento ambientalista é disso um exemplo paradigmático. As questões ambientais, enquanto preocupação generalizada, surgiram no pós- $2^{\mathrm{a}}$ Grande Guerra, com os movimentos pelo desarmamento e contra as experiências nucleares e respetivas manifestações públicas. Por exemplo, seria contra as experiências nucleares francesas, no atol de Muroroa, e americanas, na ilha de Amchitka, no Alasca, que se constituiria o Greenpeace em 1971-72 (Schmitt, 1999; Greenpeace). ${ }^{3}$ Além disso, como Sharon Beder (1996) realça, a génese do movimento ambientalista resultou da proliferação de grupos de interesse que desafiavam o poder empresarial e exigiam

3 Mais informações sobre a fundação Greenpeace disponível em: http://www.greenpeace. org/usa/en/campaigns/history/ . Acedido em 20/06/2012. 
maior controle governamental sobre os negócios. Os protestos focavam-se no impacto social e ambiental das actividades empresariais, atribuindo a culpa da degradação do meio ambiente ao crescimento desenfreado da indústria.

Neste período, muitos governos responderam com nova legislação ambiental para limitar as fontes de poluição (Beder, 1996, p. xii). Consequentemente, ao longo dos anos 70, muitas empresas tornaram-se extremamente activas politicamente, esforçando-se por promover uma agenda anti-regulação e financiando programas de relações públicas e de publicidade com o objetivo de restaurar a fé do público nos negócios e na empresa livre da regulamentação governamental. No caso norte-americano, as grandes empresas desenvolveram um verdadeiro "novo activismo corporativo", visível na criação de departamentos de public affairs e na aplicação de muitos dólares em publicidade e patrocínios com um único objectivo: melhorar a imagem e reputação da empresa (Beder, 2002: 21).

A eficácia da pressão do ativismo empresarial sobre a regulamentação governamental seria desafiada com maior força no final dos anos 80 . Com os desastres da Bhopal, Chernobyl e Exxon Valdez os movimentos ambientalistas ganharam força. A preocupação do público com o meio ambiente é também reforçada por descobertas científicas relativas ao fenómeno do ozono e ao aquecimento global. À medida que as preocupações ambientais cresceram também a desconfiança em relação às empresas aumentou - são vistas como as maiores poluidoras de água, ar, florestas, etc.. Em resposta, a comunicação verde aumenta e torna-se mais sofisticada. O pico desta tendência publicitária dá-se em 1990, com o $20^{\circ}$ aniversário do dia da Terra - um quarto de todos os produtos domésticos lançados no mercado eram anunciados como reciclável, biodegradável, amigo do ozono, ou compostável (Thien, 1993, p. 18).

Durante os anos 90, a aplicação de técnicas de relações públicas às preocupações ambientais explode. Ao serviço de grandes empresas, lobbists think thanks, e especialistas em relações públicas ambientais fazem confluir esforços para influenciar a regulamentação cada vez mais apertada sobre a responsabilidade das empresas pelo meio ambiente e índices de poluição (por ex., o Clean Air Act nos EUA e certa legislação do Parlamento Europeu). De acordo com Beder (2001, p. 9), a questão do meio ambiente seria mesmo apelidada pelos agentes de relações públicas como "a batalha pela vida e morte das RP dos anos 90" e "o tema da década". 
Desde então, o greenwash - entendido aqui como uma pseudo-acção de RSE que permite às organizações manipular uma imagem de respeito pelo ambiente - tornou-se recorrente no discurso e prática empresarial (Beder, 1996; Athanasiou, 1996). Em resposta, nas últimas décadas, proliferaram as obras dedicadas ao tema: Greenwash: The Reality Behind Corporate Environmentalism (Greer \& Bruno, 1996); Global Spin: The Corporate Assault on Environmentalism (Beder, 1996); Battling Big Business: Countering Greenwash Infiltration and Other Form of Corporate Bullying (Lubbers, 2002); Communication et environement, le pact impossible (Libaert, 2010), entre muitas outras. Claramente, são as grandes multinacionais, como a Shell ou a BP, a serem colocadas em cheque nestas obras. Em especial, devido ao seu envolvimento em estratégias complexas de activismo empresarial com o objectivo de contrariar a crescente regulamentação ambiental e responder ao interesse público na temática. Estratégias que são evidenciadas sempre que há uma diferença significativa entre a retórica de uma organização, ou seja, aquilo que comunica, e o seu real comportamento.

No geral, pode-se portanto afirmar que existe uma certa visão negativa do discurso empresarial centrado no respeito pelo meio ambiente e pelo interesse público. Ou seja, muitos são os que consideram a narrativa sobre RSE insincera per se (Bakan, 2004) e uma mera invenção das relações públicas as serviço dos interesses empresariais, muitas vezes pouco éticos (Frankental, 2001). O próprio discurso jornalístico sobre temas de RSE, interpreta de forma negativa a tensão inerente à "irresponsabilidade social corporativa" (Tench et al. 2007). Neste contexto, urge perceber até que ponto será positivo para uma empresa desenvolver programas de comunicação centrados na temática da RSE. Não será contra produtivo, para a imagem e reputação empresarial, comunicar políticas ambientais ou de interesse público? Ou melhor, como poderá uma empresa comunicar essa mesma RSE de forma a contrariar conotações negativas por parte de públicos cada vez mais cépticos?

Vários estudos têm mostrado que os profissionais de relações públicas são muitas vezes responsáveis por comunicar e legitimar a RSE das organizações (por ex., Kim e Reber, 2008; Bartlett et al, 2007). Em especial, no que concerne à elaboração e divulgação dos relatórios de sustentabilidade (Bartlett et al, 2007; Golob e Bartlett, 2007) e na gestão das relações com os públicos (Jones e Bartlett, 2009). Partindo do princípio que o profissional de relações públicas 
contribui para o delineamento estratégico dos programas comunicacionais, então, o ónus da questão pode ser colocado neste agente, que ao serviço das mais diversas empresas aconselha quando, como e o que comunicar. Com esse intuito, optou-se por conduzir um estudo exploratório sobre a temática da comunicação da RSE, junto de diretores e consultores de comunicação e relações públicas que atuam no mercado português. ${ }^{4}$

\section{A COMUNICAÇÃO ESTRATÉGICA DA RSE}

Com o objetivo principal de determinar qual a perceção dos profissionais de relações públicas sobre a comunicação de responsabilidade empresarial foram conduzidas 29 entrevistas semi-estruturadas a diretores e consultores de comunicação e relações públicas (13 diretores de comunicação de empresas privadas; 7 de empresas públicas e 9 consultores de agências de comunicação e relações públicas).

Todas as entrevistas foram presenciais e gravadas, maioritariamente, no local de trabalho do inquirido. As entrevistas foram transcritas e os dados analisados qualitativamente para responder às seguintes questões de investigação:

Q1. Qual o papel central dos profissionais de relações públicas nas organizações?

Q2. Quais os objetivos subjacentes à comunicação da RSE?

Q3. Como comunicar a RSE?

Adicionalmente, os websites das organizações onde operam os profissionais de relações públicas entrevistados foram examinados com o objectivo de possibilitar a obtenção de resultados mais aprofundados através da triangulação metodológica (Denzin e Lincoln, 1994).

4 Um estudo sobre a problemática da designação profissional em Portugal aponta para a quase inverosímil diversidade de 51 denominações no campo das relações públicas. As denominações predominantes são as que incluem a expressão "relações públicas" e/ou "comunicação e relações públicas" e ainda, aquelas onde figura o termo comunicação (por ex., diretor de comunicação) e assessor de imprensa (Tojal: 2006, 55-56). Ao longo deste artigo optamos por utilizar a expressão "relações públicas" para referir todos os profissionais que, quer pertençam aos quadros de uma organização, quer pertençam às chamadas agências ou consultoras de relações públicas, desenvolvem a comunicação desde uma perspetiva de gestão ou de assessoria à gestão. 


\subsection{O papel estratégico do comunicador profissional}

A atividade de relações públicas tem vindo a ganhar credibilidade e prestígio em Portugal ao ser apresentada com uma actividade de apoio à administração das organizações. Não só o lugar de director de comunicação tem ganho peso hierárquico como a importância atribuída aos serviços de consultoria externa em comunicação está também mais valorizada. O departamento de comunicação deve ser uma direcção ou "reportar ao presidente ou director da organização" (E17) e os consultores externos devem ter uma "ligação direta aos CEO's ou às comissões executivas das empresas" (E28). ${ }^{5} \mathrm{~A}$ importância deste pressuposto manifesta-se na possibilidade do agente de relações públicas desenvolver ou não aquela que é considerada a sua missão fundamental, o "aconselhamento estratégico":

"Penso que o sucesso do trabalho na área da comunicação depende,
em 90\%, da relação de confiança que se estabelece entre o decisor e o
apoio técnico que haja nessa área (seja um gabinete, ou um assessor).
Com base nessa relação de proximidade e de confiança, que é vital, é
que se poderá participar mais ou menos na gestão estratégica" (E23).

A prática deste "aconselhamento estratégico" é definida a partir das seguintes características:

* "Saber escutar" (E4.) A capacidade de "ouvir os sinais da sociedade" (através de estudos ou de observação informal) e "interpretar e injectar esses sinais" (E4) na organização, contribuindo assim para que ela reaja ou se adapte ao que os seus stakeholder esperam dela.

* Visão panóptica e global. As relações públicas ocupam uma "função transversal” (E27) na organização graças ao acesso a elevada quantidade de informação e a um grau muito abrangente de conhecimentos sobre os diferentes sectores da organização e das suas inter-ligações. Como todos os sectores necessitam de comunicação, compete ao comunicador "encontrar as sinergias que devem funcionar a nível estratégico" (E17).

5 Todas as expressões ou conceitos entre aspas indicam tratar-se de um "in vivo code" (Corbin e Strauss, 2008, p. 65), ou seja, uma expressão retirada ipsis verbis do discurso do entrevistado. Sempre que pertinente, os excertos citados remetem para o discurso dos entrevistados, doravante apresentados numericamente (E1, E2, E3... E29). 
* Mais e melhor informação. A crescente abertura da empresa à sociedade manifesta-se no aumento da informação disponibilizada tanto sobre os pilares económicos como sociais da organização: "A comunicação tem que ser qualquer coisa que corresponda a uma realidade. Se não se conhecer a nossa realidade só se cria ruído" (E24). Esta abertura traduz-se numa pro-actividade comunicacional.

* Construtor de relações. Qualquer estratégia de comunicação deve partir de um "mapeamento dos stakeholder" (E17) com o objectivo de se estabelecerem relações de confiança duradouras. Essas relações estão na base de todas as estratégias e são postas à prova, especialmente, quando se enfrentem situações de crise.

* Voz da consciência. O agente de relações públicas preocupa-se em "propagar valores" e "assumir causas" (E2) contribuindo para que as empresas se afirmem por aquilo que fazem, "seja pela sua responsabilidade social, pela sua ética, pelo cumprimento da regulamentação" (E11).

\section{a. Objetivos verdadeiros, estratégias eficazes}

Quando questionados sobre qual o objectivo principal subjacente à comunicação da RSE, os agentes realçaram de imediato o contributo para a imagem e reputação da empresa. Um objectivo que tanto pode ser entendido como negativo como positivo. Por um lado, vários entrevistados mostraram-se conscientes de que muita da comunicação no campo da RSE ainda só é "cosmética, o ser bonzinho" (E5), "fazer caridadezinha” (E17), levando a exageros na comunicação. Isto é, a empresa "fingir que está a fazer; dizer que faz e depois não se alterar nada" (E3). O conceito de greenwash, em concreto, é reconhecido como sinónimo de uma prática pouco ética e, consequentemente, sinal de falta de profissionalismo.

Por outro lado, todos os entrevistados sublinham o facto de a comunicação da RSE ser um contributo positivo para a imagem e reputação da organização não só por "humanizar a empresa" (E25), mas sobretudo por permitir legitimar a acção da organização na sociedade, junto de todos os seus públicos. Neste sentido, a maioria dos respondentes realçou a importância de a comunicação da RSE estar forte e claramente ligada à missão e identidade da própria organização: 


\begin{abstract}
"Tem que ser uma atitude que vem do fundo, porque se não é real, se não faz parte do ADN, então não se propaga. Quando é algo feito sem critério e que não está assumido pela empresa não tem sentido. É só uma manobra publicitária." (E2)
\end{abstract}

Todos os entrevistados defendem a importância de comunicar as políticas de responsabilidade empresarial. As principais razões enunciadas são as seguintes:

* Posicionamento da empresa. A comunicação da RSE permite que a empresa se posicione no mercado concorrencial actual e acompanhar as tendências internacionais em termos de intervenção social e ambiental e de sustentabilidade económica.

* Os públicos têm direito à informação. A comunicação da RSE situa-se mais do lado da informação do que da publicidade: "Nós temos o dever de dar a conhecer à sociedade aquilo que fazemos da mesma forma que a sociedade tem o dever de denunciar as malfeitorias que fizermos." (E14)

* Servir de exemplo. Através da comunicação a organização mostra à concorrência e a outras empresas que é possível aplicar com sucesso políticas de RSE. É importante chamar a atenção para as boas práticas na RSE.

* "Comunicar é sempre uma acto de responsabilidade empresarial" (E24). A comunicação transforma as empresas na medida em que exige uma fundamentação no real. Por ex., se se pretender elaborar um relatório de sustentabilidade, é necessário um trabalho prévio da organização nessas matérias.

\title{
b. Comunicar com conta, peso e medida
}

"Fazer bem e não dizer é uma burrice... é uma oportunidade perdida. Mas claro que sem exagero, para não se tornar ridículo” (E19). A afirmação do agente entrevistado aponta certamente para o principal problema da comunicação da RSE: o quê, quando e quanto se deve comunicar? Ou seja, saber até que ponto é aceitável comunicar sobre a acção de uma empresa sem que as mensagens provoquem desconfiança junto dos receptores e, consequentemente, se torne contraproducente para a própria imagem e reputação da empresa.

Através da análise dos dados recolhidos nas entrevistas identificaram-se alguns dos princípios ou regras que permitiram dosear a comunicação sobre esta temática, e que a seguir se enunciam: 
* Fazer primeiro, só depois comunicar;

* Não gastar mais a comunicar do que a fazer, ou seja, desenvolver uma comunicação discreta e não "comercialona" (E1);

* Praticar uma "comunicação doseada" (E14), isto é, não estar sempre a falar da temática da responsabilidade empresarial, apenas quando há motivos de orgulho (por ex., o lugar num ranking internacional como o Dow Jones Sustentability Index, ou obter uma certificação de responsabilidade social ou ambiental, como a Norma SA8000 e o Eco-label);

* Não abusar da comunicação publicitária, mas antes recorrer à assessoria de imprensa;

* Desenvolver muitos planos de comunicação inter-pessoal e de eventos (por ex., reuniões, congressos, etc.);

* Não comunicar sobre tudo o que se faz no âmbito da responsabilidade empresarial, só o que é de interesse do grande público;

* Deixar que os outros falem sobre o que a empresa faz (os parceiros, como as ONG's, ou os próprios media).

\section{REFLEXÃO CONCLUSIVA}

O conceito de responsabilidade social empresarial (RSE) parece ter-se tornado no "novo mantra" do mundo dos negócios (Munschi e Kurian, 2005, p. 414). No entanto, muitos são aqueles que vêm nesta política empresarial apenas mais uma mera técnica propagandística, muitas vezes sem qualquer fundamento no real, cujo objectivo último e único reside em melhorar a imagem e reputação de uma empresa.

O desenvolvimento desta opção comunicacional por parte das mais variadas organizações foi largamente influenciado pela pressão dos movimentos cívicos, por ex., ecologistas, que alertam a opinião pública para as contradições de muitas multinacionais - entre dizer e fazer. Sem dúvida que o desenvolvimento dos movimentos activistas provocara claras mudanças na forma como as empresas interagiam com a sociedade e, consequentemente, na forma como comunicavam com a sociedade. Mas, a questão que prevalece é de teor ético. Ou seja, até que ponto a comunicação da RSE tem sido desenvolvida de forma transparente e responsável, ou pelo contrário, de forma meramente instrumental, com a sobrevalorização do valor da imagem verde, por ex., para o sucesso empresarial? 
Na opinião dos profissionais de relações públicas entrevistados a operar no mercado português, o lugar estratégico que a comunicação ocupa nas empresas não parece deixar lugar para dúvidas - é importante comunicar sobre o posicionamento responsável das organizações, mas, com conta, peso e medida. Para que a comunicação da RSE não se torne uma "communication externe en boomerang" (Libaert, 2010, p. 93), ou seja, uma comunicação perversa, que se vira contra o próprio emissor das mensagens, certos princípios básicos devem ser continuamente tomados em consideração. Em $1^{\circ}$ lugar, tomar a decisão de comunicar só e apenas quando o tema da RSE estiver no coração da missão da organização; em $2^{\circ}$ lugar, desenvolver uma comunicação humilde e moderada, em especial, sem o recurso a investimentos publicitários gigantescos; e, finalmente, em $3^{\circ}$ lugar, procurar que as mensagens sobre a acção da organização sejam endossadas de forma mediática, por líderes de opinião ou por ONGs. No seu conjunto, a adopção destes princípios básicos permitirá afirmar não só o grau de responsabilidade da comunicação da RSE mas também, o papel fundamental do profissional de comunicação na gestão estratégica da comunicação das organizações.

Apesar das limitações imanentes a um estudo exploratório, espera-se que os dados obtidos possam servir de ponto de partida para o desenho de uma investigação mais abrangente e aprofundada sobre os limites e peculiaridades da comunicação da RSE na perspetiva das relações públicas e, assim, contribuir para uma comunicação estratégica no mundo empresarial que se pretende eficaz mas também pública e socialmente responsável.

\section{REFERÊNCIAS}

ATHANASIOU, Tom. Divided planet: The ecology of rich and poor. Boston: Little, Brown \& Company, 1996.

BAKAN, Joel. The Corporation: the pathological pursuit of profit and power. Londres; Constable \& Robinson, 2004.

BARTLETT, Jennifer; TYWONIAK, Stephane; HATCHER, Caroline. Public relations professional practice and the institutionalisation of CSR. Journal of Communication Management, 11 (4), pp. 281-299, 2007.

BEDER, Sharon. Global Spin, 2001. Recuperado a 10 de Maio 2012, de http://ro.uow.edu.au/ cgi/viewcontent.cgi?article $=1050 \&$ context=artspapers

BEDER, Sharon. Global spin: The corporate assault on environmentalism. Devon: Green 
Books, 2002.

BEDER, Sharon. The nature of sustainable development. Melbourne: Scribe Publications, 1996.

BERNAYS, Edward L. The engineering of consent. Norman: University of Oklahoma Press, 1955.

BOWEN, Howard R. Social responsibilities of the businessman. Nova lorque: York, Harper \& Row, 1953.

CARROLL, Archie B. Corporate social responsibility: Evolution of a definitional construct. Business and Society, vol. 38 (3), p. 268-295, 1999.

COCHRAN, Philip L., The evolution of corporate social responsibility. Business Horizons, $\mathrm{n}^{\circ}$ 50, p. 449-454, 2007.

CORBIN, Juliet M.; STRAUSS, Anselm L. Basics of qualitative research: techniques and procedures for developing grounded theory. Londres: Sage, 2008.

CUTLIP, Scott M., CENTER, Allen H., BROOM, Glen M. Effective public relations. $6^{\text {a }}$ ed. Englewood Cliffs: Prentice-Hall, 1986.

DENZIN, Norman K.; LINCOLN, Y. (ed.). The Sage handbook of qualitative research. Thousand Oaks: Sage, 1994.

FRANKENTAL, Peter. Corporate social responsibility: A PR invention?. Corporate Communications, 6 (1), pp. 18-23, 2001.

FREDERICK, William C. From CSR1 to CSR2: The maturing of business-and-society thought. Graduate School of Business: University of Pittsburgh, working paper 279, 1978.

GOLOB, Ursa; BARTLETT, Jennifer. Communicating about corporate social responsibility: A comparative study of CSR reporting in Australia and Slovenia. Public Relations Review, 33 (1), pp. 1-9, 2007.

GREER, Jed; BRUNO, Kenny. Greenwash: The reality behind corporate environmentalism. Nova Iorque: Apex Press, 1996.

GRUNIG, James E.; HUNT, Todd. Managing public relations. Nova lorque: Holt, Rinehart \& Winston, 1984.

HAYWARD, Philip. The real deal? Hotels grapple with green washing. Lodging Magazine, Fevereiro, 2009.

JONES, Kevin; BARTLETT, Jennifer. The strategic value of corporate social responsibility: a relationship management framework for public relations practice. PRism, 6(1), 2009.

KIM, Soo-Yeon; REBERB, Bryan. Public relations' place in corporate social responsibility: Practitioners define their role. Public Relations Review, 34 (4), pp. 337-342, 2008.

LESLY, Philip. Lesly's handbook of public relations and communications. Chicago: Probus Publishing Company, 1991. 
LIBAERT, Thierry. Communication et environment, le pacte impossible. Paris: PUF, 2010.

LUBBERS, Eveline. Battling big business: Countering greenwash, infiltration and other forms of corporate bulllying. Monroe: Common Courage Press, 2002.

MUNSCHI, Debashish; KURIAN, Priya. Imperializing spin cycles: A postcolonial look at public relations, greenwashing, and the separation of public. Public Relations Review, 31 (4), pp. 513-520, 2005.

SCHMIDT, Luísa. Ambiente e natureza no écran: emissões televisivas, remissões culturais. Lisboa: ICS-UL/ISCTE, Tese de Doutoramento, policopiado, 1999.

TENCH, Ralph; BOWD, Ryan; JONES, Brian. Perceptions and perspectives: corporate social responsibility and the media. Journal of Communication Management, 11 (4), pp. 348-370, 2007.

THIEN, Alan. Can't live without it. World Watch, May/June, 18, 1993.

TOJAL, M. (coord.) Relações Públicas. O reconhecimento da profissão em Portugal. Maia: Publismai, Cadernos Universitários, n. ${ }^{\circ}$ 2, 2006.

RECEBIDO EM: 18/11/2013

ACEITO PARA PUBLICAÇÃO: 19/12/2013

\section{Gisela Gonçalves}

Possui doutorado e mestrado em Ciências da Comunicação pela Universidade da Beira Interior. É professora desde 2003 no Departamento de Comunicação e Artes da UBI onde dirige o Mestrado em Comunicação Estratégica. Desenvolve a sua investigação no Laboratório de Comunicação On-line (LabCom) centrando a sua pesquisa e publicação no campo das teorias das relações públicas, comunicação política e ética da comunicação. Coordena atualmente a Secção de Comunicação Organizacional e Estratégica da European Communication Research and Education Association (ECREA). 
